\title{
الوضع الراهن للموارد المائية واستخداماتها في دول حوض النيل
}

\author{
الباحث: عوجان مبارك عوجان دعيم العرادة
}

باحث دكتوراه - معهد البحوث والدراسات الأفريقية ودول حوض النيل-

جامعة أسوان

طلعت حافظ اسماعيل

استاذ الاقتصاد الزراعي المتفرغ- كلية الزراعة - جامعة اسيوط.

\section{احمد ابراهيم عحم أحمد}

استاذ الاقتصاد الزراعي المساعد - كلية الزراعة بأسيوط- جامعة الازهر 


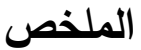

وتبرز النتائج أن الكونغو الديمقراطية تحظي بالنصيب الاكبر علي الاطلاق من

المياه السطحية في دول حوض النيل ، ولكن لا يعتبر نهر النيل الابيض الذي تشترك في حوضه المائي المصدر الاساسي لهذه الموارد ، بل يعتبر نهر الكونغو هو المصدر الاساسي، ذلك بعكس اثيوبيا الذي يعتبر النيل الازرق وروافده، والذي ينبع منها هو المصدر الاساسي للمياه السطحية في اثيوبيا حيث تبلغ مواردها من نهر النيل

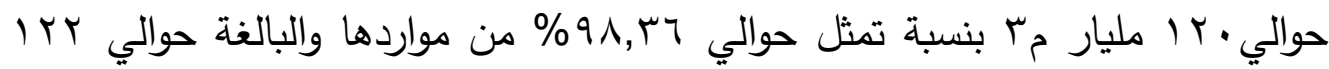

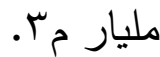

وعند دراسة توزيع المياه الجوفية المتجدة والغير متجدده في دول حوض النيل

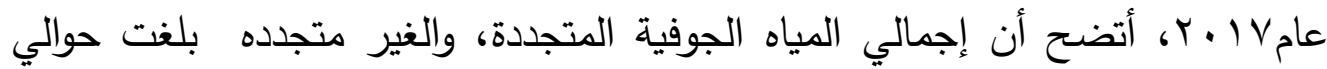

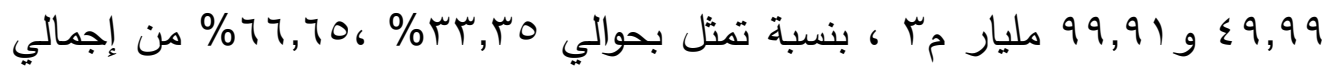
المياه الجوفية في دول حوض النيل.

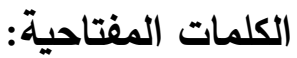

استخدامات الموارد المائية، دول حوض نهر النيل، المياه الجوفية.

Current Status of water resources and their uses in the Nile Basin Countries 


\section{Summary:}

The results show that the Democratic Republic of the Congo has the largest share of surface water ever in the countries of the Nile Basin, but the White Nile River, which shares its water basin, is not the main source of these resources, but the Congo River is the main source, unlike Ethiopia, which is the Blue Nile and its tributaries., Which stems from it is the main source of surface water in Ethiopia, where its resources from the Nile River are about 120 billion cubic meters, at an estimated rate of $98.36 \%$ of its resources, which amount to about 122 billion

Upon studying the distribution of renewable and non-renewable groundwater in the Nile Basin countries in 2017, the total renewable and non-renewable groundwater reached about 49.99 and 99.91 billion cubic meters, for an estimated rate of 33.35\%, $66.65 \%$ of the total groundwater In the Nile Basin countries.

With an estimate of the degree of (Gini) coefficient for the distributive justice questionnaire for Nile water resources, it reached about (0.29), which indicates that the distribution of water in its current quantities tends to distributive justice, but justice was not achieved according to the value of the Gini coefficient, which increases the fairness of distribution with a decrease in its value.

By studying the distribution of the use of water resources in the Nile Basin countries in 2017, the agricultural sector occupied the 
first rank 100,02 billion $\mathrm{m} 3$, with an estimated rate of about $81.91 \%$ of the total user and pallet about 122,59 billion $\mathrm{m} 3$, followed by domestic use and the industrial sector with an estimated rate of about $14,78 \%, 7.76 \%$ of the total water resources used, respectively

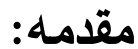

تعتبر المياه من أهم الموارد الطبيعية لبقاء واستمرار الحياه علي سطح الارض، والمحقق الرئيسي لإحداث التتمية الاقتصادية والزراعية للدول الغنية والفقيرة علي حد سواء، وتساعد توفرها بصفه مستمرة الي توفير فرص التنمية المستدامة وتحقيق خطط وطموحات الدول في ذلك .

ويعتبر نهر النيل بفرعيه الابيض والأزرق ورافدهم من أهم المصادرة المائية لدول حوض النيل سواء دول المنبع او دول المجري المصب ، ومن الاهمية بمكان الوقوف علي الوضع الراهن والعمل علي تتميه هذه الموارد والمحافظة عليها، وذلك من خلال ترشيد استخداماتها في ظل الظروف والمتغيرات الحالية، وضمان فرص التمية المشتركة والحقوق القانونية لجميع الاعضاء، وذلك للحد من نشوب نزاعات علي هذه الموارد، قد تتطور الي نزاعات سياسيه وعسكريه لدول حوض النيل، وذلك باعتبار الموارد المائية النيلية من أهم الموارد المائية لا غلب دول الحوض فيما عدا الكونغو 
الديمقراطية التي تعتمد على مصادرها المائية من نهر الكونغو ذا الوفرة المائية العالية، ويشترك في حوض النيل كل من الكونغو وبورندي وروندا واوغندا وتتزانيا وكينيا وأثيوبيا واريتريا وجنوب السودان والسودان، ومصر ـ(r-منار) اشكالية البحث:

تعتمد معظم دول حوض النيل وبالأخص مصر والسودان علي نهر النيل كمصدر رئيسي للموارد المائية ، والتي تعتبر شريان الحياه لهذه الشعوب، وفي ظل زيادة الاستخدامات المائية في كافة القطاعات المستهكة للماء ، والزيادة المضطردة في عدد السكان لهذه الدول ، بجانب زيادة الطموحات بإحداث تتميه اقتصاديه وزراعيه مستدامه مما يؤدي الي زيادة الاحتياج لهذه الموارد ، وقد بزرت وتصاعدت في الآونة الأخيرة حدة الخلافات بين الدول الاعضاء حول تقسيم وحق استغلال موارد نهر النيل المائية ، وذلك بين دول المنبع ودول المجرى والمصب، فكان من الأهمية القاء الضوء على الوضع الحالي والمتاح من الموارد المائية بمصادرها المختلفة في دول حوض كواهم استخداماتها في الوقت الراهن ، وذلك للعمل علي تتميتها وزيادة كفاءة استخداماتها.

\section{الهدف من البحث:}

استهدف البحث القاء الضوء علي الموقف الراهن للموارد والاستخدامات المائية لدول حوض النيل من خلال دراسة كل من : 
1- الوضع الراهن للمتاح من الموارد المائية في دول حوض النيل.

r- العدالة التوزيعية للموارد المائية في دول حوض النيل.

r- أهم قطاعات استخدام المياه في دول حوض النيل .

الطربقة البحثية ومصادر البيانات :

اعتمد البحث على التحليل الإحصائي الوصفي في توضيح المتغيرات البحثية ، وتم الاستعانة ببعض المقاييس الإحصائية الأخرى ذات الصلة بتحقيق أهداف البحث، ولقد اعتمدت البحث على البيانات المنشورة من قبل الجهات العالمية والمحلية لدول حوض النيل والمعنية بالموارد المائية ، والتي منها المنظمة العالمية للغذاء والزراعة(FAO)، من خلال الموقع الاليكتروني (FAO Stat)، وبعض الإصدارات العلمية والجهات المختصة الاخرى بدول حوض النيل.

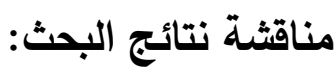
اولاً: الوضع الراهن للمتاح من الموارد المائية التقليدية في دول حوض النيل. تنقسم الموارد المائية الي الموارد المائية التقليدية، وهي تعتبر من الموارد الطبيعية والتي لم يتذخل في تكوينها وايجادها العنصر البشري، وهي عباره عن مياه الانهار والامطار والمياه الجوفية والأرضية وغيرها من المياه الطبيعية، والتي تعتبر عماد الموارد المائية بكافة استخداماتها الاروائيه والبشرية وغيرها. 
أ-توزيع المساحة الكلية والصالحة للزراعة ومساحه الحوض المائي في دول حوض التيل. بمطالعة بيانات الجدول رقم (1) يتضح أن المساحة الكلية لدول حوض النيل الاحدى عشر، والتي تشمل كل من بورندي وروندا وتنزانيا وكينيا والكونغو الديمقراطية

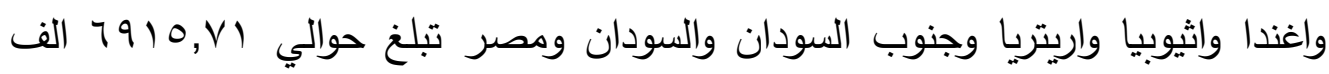
كمr عام V V P r وتثغل كل من السودان واثيوبيا ومصر المساحة الاكبر من ضمن

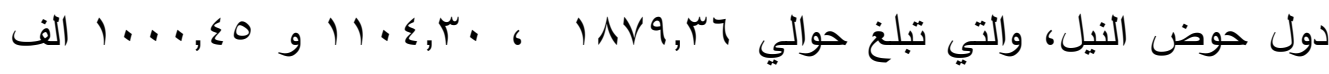

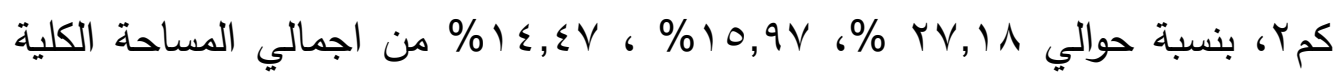
علي الترتيب، فيما تعتبر روندا الاقل في المساحة بنسبة تبلغ حوالي ر؟,، ٪ من إجمالي المساحة الكلية . 
جدول رقم (1) المساحة الكلية ومساحه الحوض المائي في دول حوض التيل عام VI ـ Y.

\begin{tabular}{|c|c|c|c|c|}
\hline (\%) من اجمالي دول & 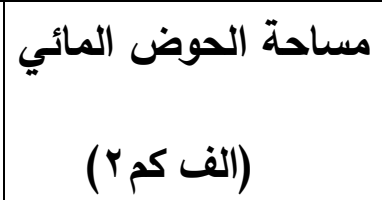 & 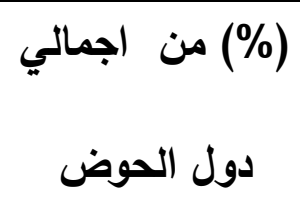 & 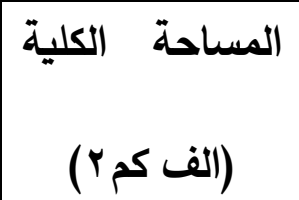 & بيان \\
\hline$\cdot, 7$ & $r \cdot, \varepsilon \cdot$ & $\cdot, \varepsilon \cdot$ & rA r rV & بوزندي \\
\hline$\cdot, \varepsilon$. & $1 \%, 7$. & $\cdot, r \wedge$ & $r q, r r$ & روندا \\
\hline$r, V$. & $91, \wedge$. & $i r, v$. & $q \leq V, r$. & تنزانيا \\
\hline $1,0$. & $01, \ldots$ & $\Lambda, r q$ & $\Delta \wedge \cdot, r V$ & كينيا \\
\hline$\cdot, v$. & $r r, \Lambda$. & $\varepsilon, 90$ & $r \leqslant r, \ldots$ & الكونغو الديمقراطية \\
\hline
\end{tabular}




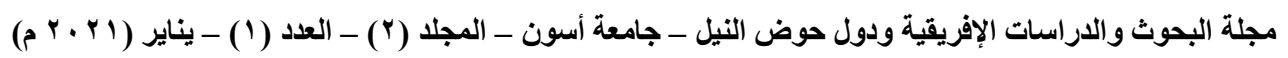

\begin{tabular}{|c|c|c|c|c|}
\hline$V, \varepsilon 1$ & $r \circ 1,7$ & $\varepsilon, \varepsilon q$ & $r \leqslant 1,00$ & اوغندا \\
\hline 11,11 & $r q v, \Lambda$ & $10,9 V$ & $11 \cdot \varepsilon, \mu$. & اثيوبيا \\
\hline$\cdot, \wedge$ & $r V, r$. & 1,17 & $|r|, q$. & اريتريا \\
\hline 17,07 & $0 Y Y, \varepsilon$ & q, rr & & جنوب السودان \\
\hline$\varepsilon v, 11$ & $17 \ldots$ & $r v, 1 \wedge$ & I $\wedge \vee q, r q$ & السودان \\
\hline $1 \cdot, 01$ & rov... & $1 \varepsilon, \varepsilon V$ & $1 \cdots, \varepsilon 0$ & مصر \\
\hline $1 \ldots$ & . . & $1 \ldots$ & 9910,71 & لي \\
\hline
\end{tabular}

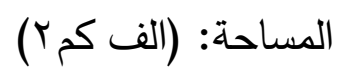

_المصدر : جمعت وحسبت من : منظمة الأغذية والزراعة(FAO)، قاعدة بيانات ( FAO 
ويشير نفس الجدول الي ان مساحة الحوض المائي في هذه الدول والذي يعني

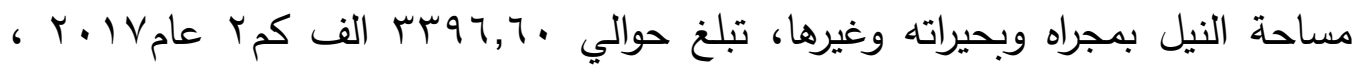
وتشغل السودان وجنوب السودان واثيوبيا الحيز الاكبر من مساحة الحوض المائي بحوالي

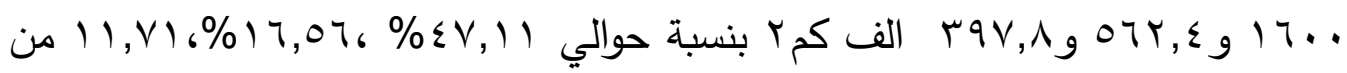
إجمالي مساحة الحوض المائي علي الترتيب ، فيما تعتبر روندا الاقل مساحة للحوض المائي بنسبة تبلغ حوالي ع, • \% من إجمالي المساحة الكلية للحوض المائي • ب- الموارد المائية التقليدية المتاحة حسب مصدرها لاول حوض النيل. يتضح من مطالعة بيانات الجدول رقم (Y) وذلك بتوزيع كميات الموارد المائية التقليدية في دول حوض النيل حسب المصدر، آنها تتقسم الي الموارد المائية السطحية وهي تشمل مياه نهر النيل وبحيراته الثابتة والناتجة خلال الفيضان الموسمي للنهر، وتبلغ

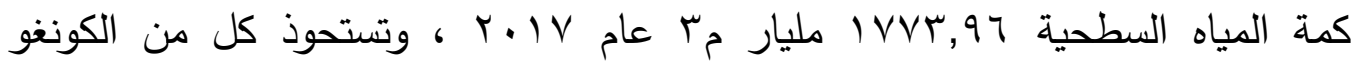
الديمقراطية ،واثيوبيا، وتتزانيا علي كمية المياه السطحية الاكبر في دول حوض النيل ،

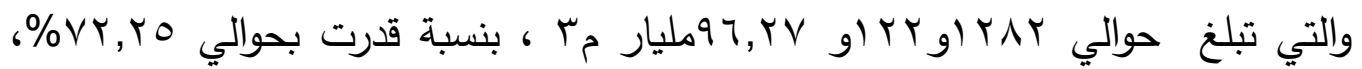

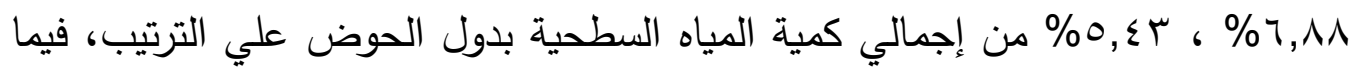
تعتبر روندا الاقل في كمية المياه السطحية بنسبة قدرت بحوالي \٪, • \% من إجمالي كمية المياه السطحية المتاحة في دول حوض النيل. 
و تدلل تلك النتائج علي ان: الكونغو الديمقراطية تحظي بالنصيب الاكبر علي الاطلاق من المياه السطحية في دول حوض النيل، ولكن لا يعتبر نهر النيل الابيض الذي تشترك في حوضه المائي المصدر الاساسي لهذه الموارد ، بل يعتبر نهر الكونغو هو المصدر الاساسي ، بعكس اثيوبيا الذي يعتبر النيل الازرق وروافده، والذي ينبع منها هو المصدر الاساسي للمياه السطحية في اثيوبيا حيث تبلغ مواردها من نهر النيل

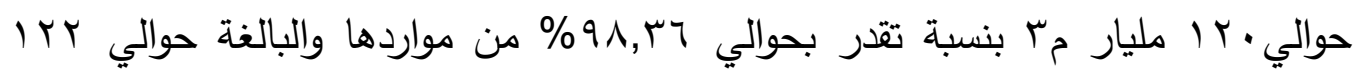
مليار مب(ع- منظمة الأغذية والزراعة).

ويشير نقس الجدول عند توزيع المياه الجوفية المتاحة، وهي تثمل المياه المتجددة

والغير متجدده في دول حوض النيل، وأن إجمالي كمية المياه الجوفية تبلغ

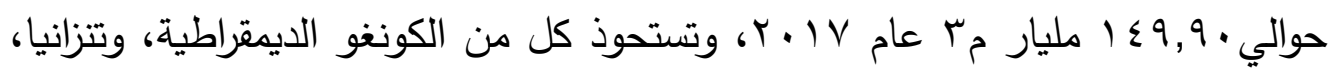
واوغندا علي كمية المياه الجوفية الاكبر في دول حوض النيل، والتي تبلغ حوالي بـ

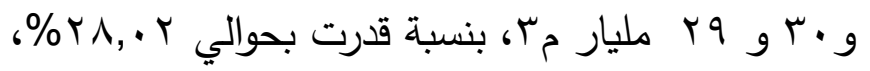




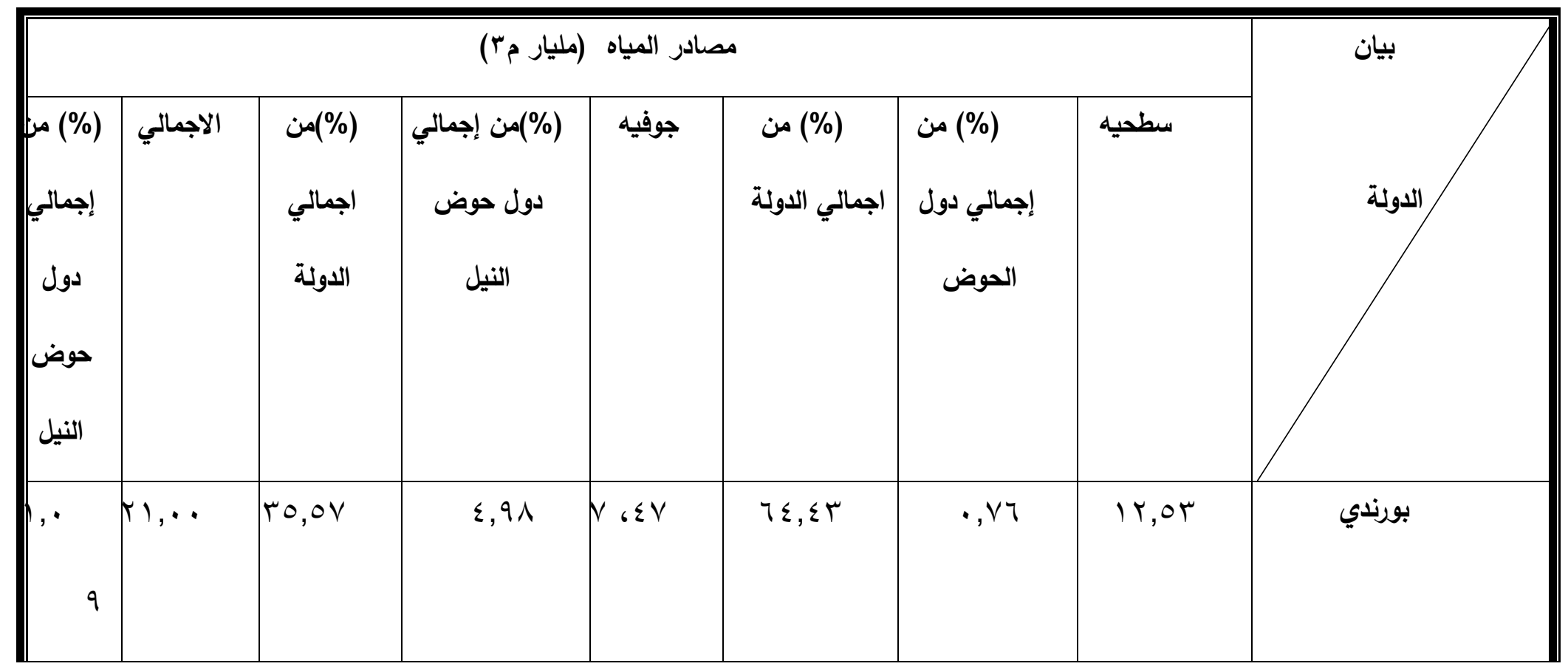


مجلة البحوث و الاراسات الإفريقية ودول حوض النيل - جامعة أسون - المجلد (r) - العدد ( ) - يناير ( ا ب r م)

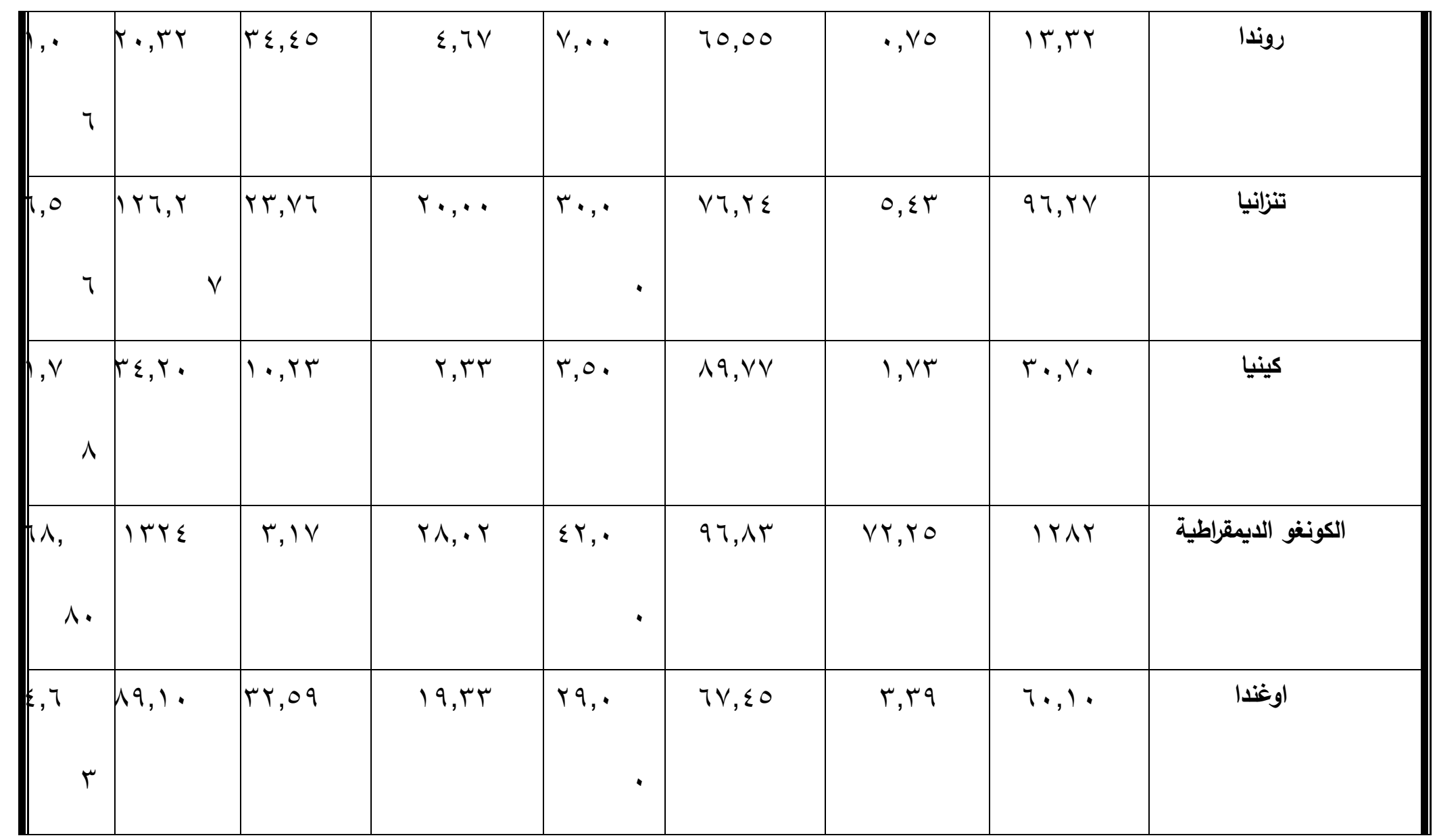


عوجان مبارك عوجان دعيم العرادة وآخرون، الوضع الراهن للموارد المائية واستخداماتها في دول حوض النيل.

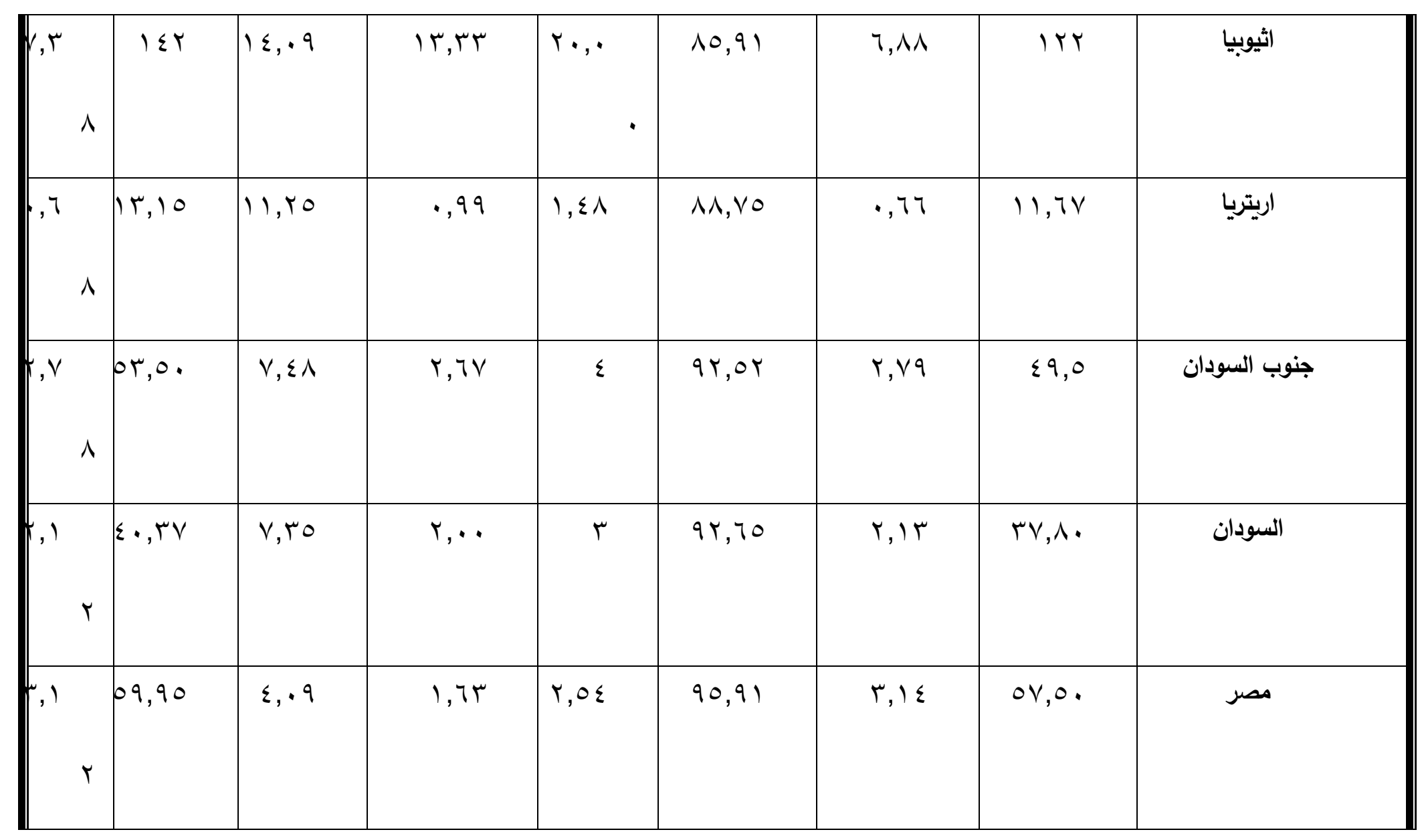


مجلة البحوث و الاراسات الإفريقية ودول حوض النيل - جامعة أسون - المجلد (r) - العدد ( ) - يناير ( ا م r م)

\begin{tabular}{|c|c|c|c|c|c|c|c|c|}
\hline 1 & $\begin{array}{c}9 r T \\
\wedge 7\end{array}$ & $\vee, \vee q$ & $1 \ldots$ & $\begin{array}{r}1 \leqslant 9 \\
.9\end{array}$ & $q r, r_{1}$ & $1 \ldots$ & IVVT,q & الاجمالي \\
\hline
\end{tabular}

جدول رقم (Y) توزيع كميات الموارد المائية التقليدية المتاحة حسب مصدرها لاول حوض النيل عام V Y Y. .

المصدر : جمعت وحسبت من : منظمة الأغذية والزراعة(FAO)، قاعدة بيانات (FAO Stat).htt/www.fao.org.) 
•r . تعتبر مصر الاقل في كمية المياه الجوفية بنسبة قدرت بحوالي بآ, ا\% من إجمالي كمية المياه الجوفية المتاحة في دول حوض النيل . وبتوزيع نسبة كميات المياه السطحية والجوفية لكل دوله علي حدي ، يبين نفس الجدول أن كل من الكونغو الديمقراطية ومصر والسودان تثغل كميات المياه السطحية

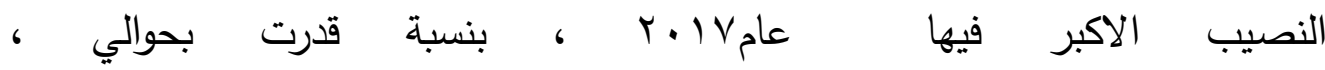

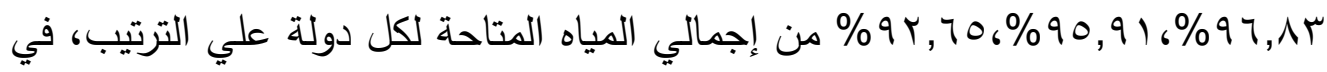
حين تشغل كميات المياه الجوفية في كل من بورندي ، وروندا، واوغندا النصيب الأكبر

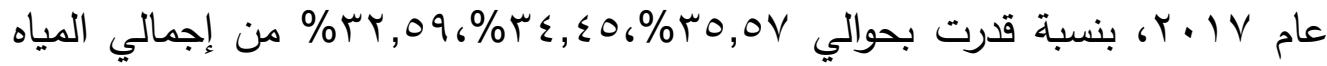
المتاحة لكل دوله علي الترتيب. وبمقارنة كميات إجمالي المياه المتاحة ،السطحية والجوفية لدول حوض النيل في عام VI P Y، تبين بيانات نفس الجدول أن كمية المياه السطحية تشغل المرتبة الاولي،

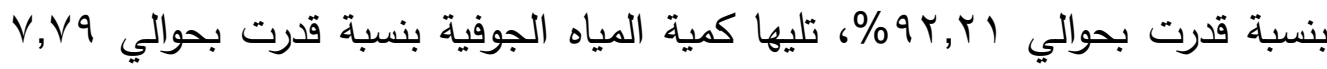

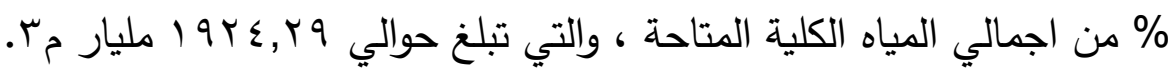
واخيراً يشير نفس الجدول المشار أليه علي إجمالي المياه المتاحة في دول الحوض والتي تثمل المياه السطحية والجوفية ، فقد تبين من خلال البيانات ان كل من الكونغو

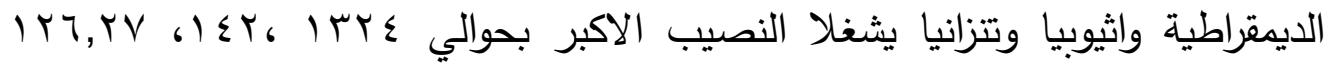




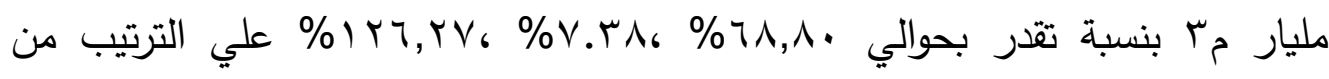
إجمالي المياه المتاحة في دول حوض النيل.

ج- الموارد المائية السطحية المتجدة ونسبة الاعتمادية لاول حوض النيل.

تعتبر الموارد المائية السطحية المتجددة اهم مصادر المياه لدول حوض النيل،

وتنقسم هذه الموارد الي قسمين :

القسم الاول :الموارد المائية السطحية الخارجية ،وهي التي تكون من منابع خارجيه

ويمر المجري المائي لهذه المنابع في اراضي الدولة ، وتعتبر دول مصب ومرور وذلك كالأنهار الدولية والبحيرات المشتركة.

القسم الثاني: الموارد المائية المتجددة الداخلية ،هي الموارد المائية التي تتبع في الدولة او تشترك فيه، كالأنهار الدولية التي تتبع في الدولة او الانهار والبحيرات

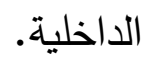

وتثير نسبة الاعتمادية(r- فوزي) الي نسبة اجمالي موارد المياه المتجددة التي تتبع او

تتشأ خارج الدولة وهذا المؤشر يتراوح ما بين صفر -... ، وكلما ذاد المؤشر دلل علي اعتمادية الدولة علي المصادر المائية الخارجية والعكس .

وتثير بيانات جدول رقم (r) ، الي توزيع المياه السطحية المتجدة الداخلية

والخارجية لدول حوض النيل عامV| •r، حيت بلغت كمة المياه السطحية المتجدة

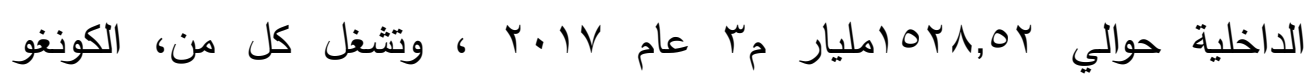


الديمقراطية، وأثيوبيا وتنزانيا كمية المياه السطحية المتجددة الداخلية الاكبر في دول

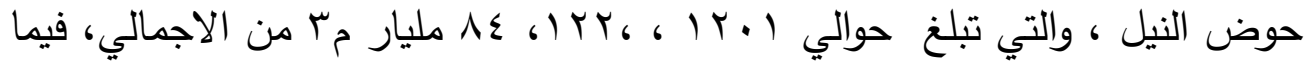
تعتبر مصر الاقل في كمية المياه السطحية المتجدة الداخلية بكمية قدرت بحوالي

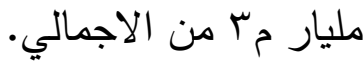




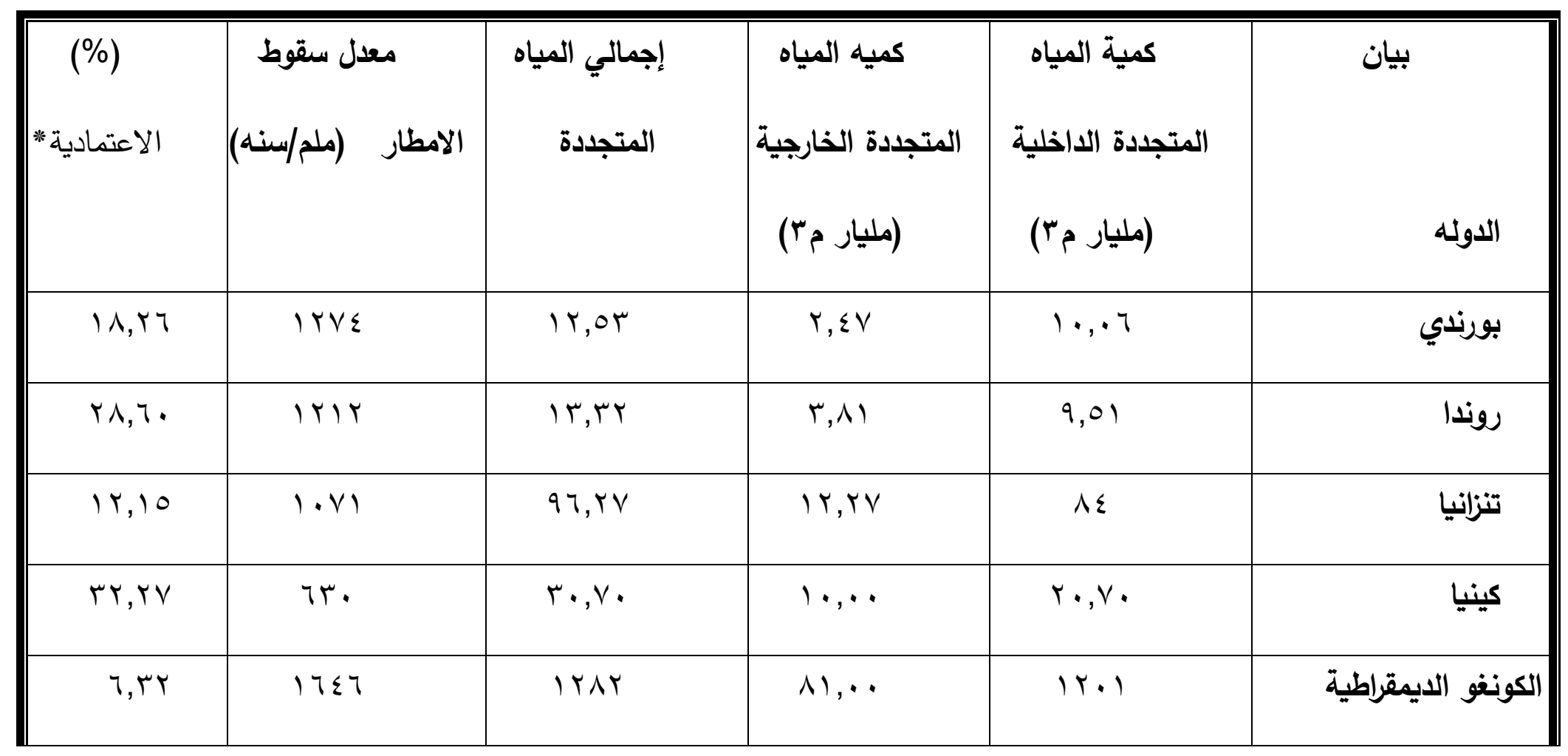




\begin{tabular}{|c|c|c|c|c|c|}
\hline 10,11 & 111 & $7 \cdot, 1$. & r 1,1 . & rq,.. & اوغندا \\
\hline صفر & $\wedge \leq \Lambda$ & IrT & . & IrT & اثيوبيا \\
\hline r, & T^乏 & $11,7 \mathrm{~V}$ & $\cdot, \varepsilon r$ & $11, r_{0}$ & اريتريا \\
\hline$\leq V, \leq V$ & roo & $\varepsilon q, 0$ & . & rq,.. & جنوب السودان \\
\hline$\wedge q, \leq r$ & ro. & rV,^. & . 1, & $\varepsilon, \cdots$ & السودان \\
\hline$q \wedge, Y q$ & 01 & ov,o. & $07,0$. & $1, \ldots$ & مصر \\
\hline $1, O r$ & $19 \cdot 1$ & IVVr,q & $r \varepsilon \varepsilon, V V$ & IOKA,Or & \\
\hline
\end{tabular}

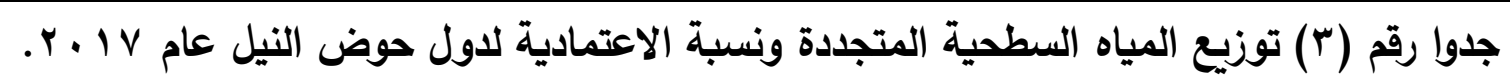

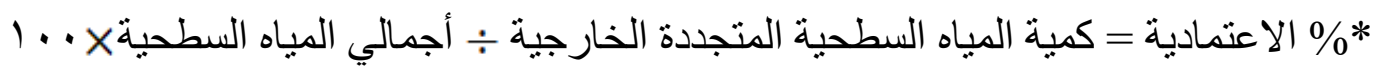
المصدر : جمعت وحسبت من : منظمة الأغذية والزراعة(FAO)، قاعدة بيانات (FAO Stat).htt/www.fao.org.) 
وتثير بيانات نفس الجدول، عند توزيع المياه السطحية المتجدة الخارجية، حيت

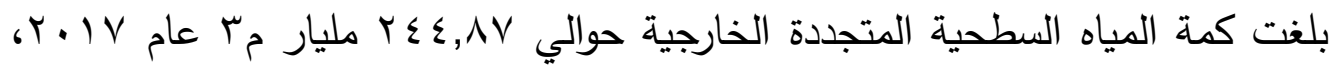
وتثغل كل من الكونغو الديمقراطية ومصر والسودان كمية المياه السطحية المتجددة

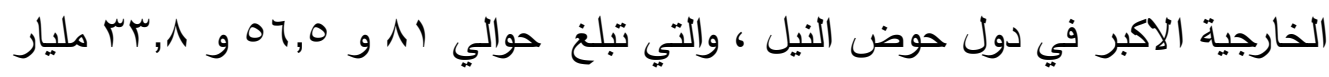
مج من الاجمالي ، فيما تعتبر اثيوبيا الاقل علي الاطلاق لعدم اعتمادها علي اي مصادر مائية سطحيه متجدده خارجيه. واخيراً بتقدير نسبة الاعتمادية لكل دول حوض النيل، يبين نفس الجدول ان كل من مصر والسودان وجنوب السودان اكثر بلدان حوض النيل اعتماداً علي المياه

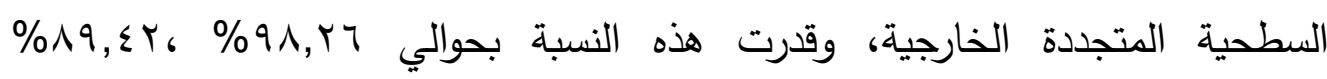

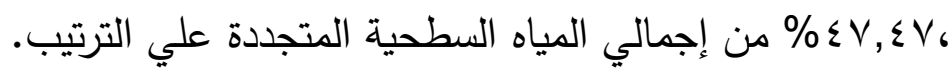
مما يدلل علي اعتماد هذه الدول علي المصادر المائية المتجدة من خارج اراضيها، ويكون بذلك هذه الدول عرضه لنقص مواردها في حالة عدم التزام دول المنبع بالاتفاقيات الدولية او الثنائية الموقعة بين هذه الدول، وهوما تتعرض له كل من مصر والسودان في الوقت الراهن مع اثيوبيا باعتبارها دولة المنبع لغالبيه مواردهم المائية ، وتسعي مصر والسودان الي عدم نشوب نزاع مائي بينهم وبين اثيوبيا وعدم الاضرار 
بحصتهم المقررة حسب الاتفاقيات الموقعة والمقرة دولياً، وذلك عن طريق المفاوضات الجارية، حتي وقت اعداد البحث.

\section{دـ المياه الجوفية المتجددة والغير متجدده في دول حوض النيل.}

تثير بيانات جدول رقم(ع)، الي توزيع المياه الجوفية المتجددة والغير متجدده في دول حوض النيل عام V ا ب، حيت بلغت إجمالي المياه الجوفية المتجددة، والغير متجدده حوالي 9,99£ و (99,9 مليار קץ ، بنسبة تمثل حوالي هr,rr\% (77,70،

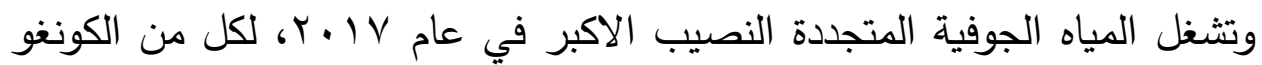

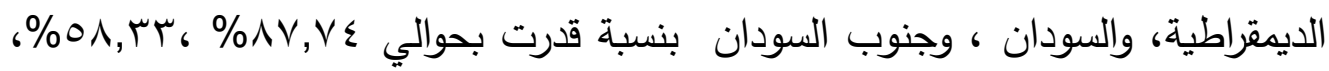
هr, זه\% من إجمالي المياه الجوفية في كل دوله علي الترتيب . وتشغل المياه الجوفية الغير متجدده النصيب الاكبر في عام V ل IT، لكل من

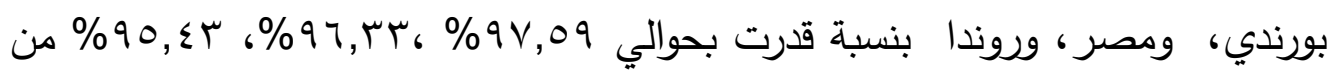
إجمالي المياه الجوفية في كل دوله علي الترتيب .

وهذه النتائج توضح أن مصر توجد مع الدول الاكثر احتياجاً للمياه السطحية المتجددة ، وذلك لانخفاض نصيبها من المياه الجوفية المتجددة ، والتي قد تعتمد عليها

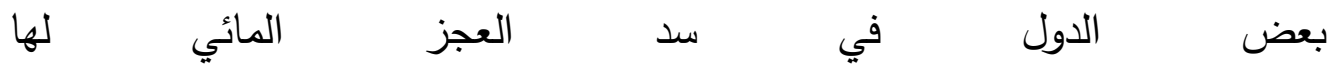




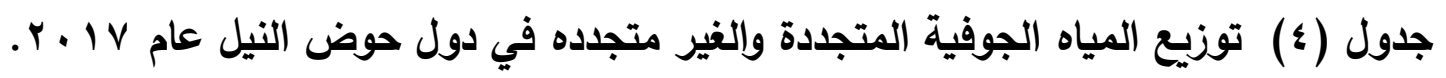

\begin{tabular}{|c|c|c|c|c|c|}
\hline إجمالي المياه & المياه الجوفية في من اجمالي & كميه المياه & |اجمالي المياه & الجوفية المتجدية المياه & بيان \\
\hline$V, \varepsilon V$ & $৭ \vee, ० q$ & $v, r q$ & $r, \& 1$ & $\cdot, 11$ & بورندي \\
\hline$v, \ldots$ & $q 0, \leqslant r$ & 8,71 & $\varepsilon, \diamond V$ & $\cdot, r r$ & روندا \\
\hline$r_{.}, \ldots$ & $\wedge \uparrow, 4 \vee$ & $r q, \ldots$ & IT, & $\varepsilon$ & تنزانيا \\
\hline$r, 0$. & $v 1,1 \leqslant$ & $r, r q$ & 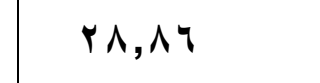 & $1, .1$ & كينيا \\
\hline
\end{tabular}




\begin{tabular}{|c|c|c|c|c|c|}
\hline$\varepsilon r, \cdots$ & $1 Y, Y Y$ & 0,10 & $\Lambda \vee, \vee \varepsilon$ & r, & الكونغو الديمقراطية \\
\hline$p q, \ldots$ & $q r, r \wedge$ & $r V, \cdot 0$ & $Y, V Y$ & 1,90 & اوغندا \\
\hline$r \cdot, \cdot$ & $9 \varepsilon, 90$ & 11,99 & 0,0 & $1, \cdot 1$ & اثيوبيا \\
\hline $1, \varepsilon \wedge$ & $7 \cdot, 11$ &., 9 & $p q, 19$ & $\cdot, \diamond \wedge$ & اريتريا \\
\hline$\varepsilon$ & $\varepsilon r, V \bullet$ & $1, v 0$ & $\bullet \neg, Y 0$ & $r, Y \circ$ & جنوب السودان \\
\hline$r$ & $\varepsilon 1,7 V$ & $1, r o$ & O & $1, \vee 0$ & السودان \\
\hline$r, 0\}$ & $q q, \mu$ & r, & $r, 7 v$ &., .9 & مصر \\
\hline $1 \leqslant 9,9$. & 77,70 & 99,91 & هץ, & $\varepsilon 9,99$ & \\
\hline
\end{tabular}

المصدر : جمعت وحسبت من : منظمة الأغذية والزراعة(FAO)، قاعدة بيانات (FAO Stat).htt/www.fao.org.) 
ثانياً- نسبة التركز والعدالة التوزيعية للموارد المائية النيلية في دول حوض النيل.

يتناول هذا الجزه نسبة التركز والعدالة التوزيعية لمياه نهر النيل المتاحة بين دول حوضه المائي ، وذلك باستخدام معامل " جيني"(') لبيان مدى عدالة توزيع المياه بين الدول الاعضاء.

ويعتبر معامل "جيني" من ابرز أدوات القياس المستخدمة عند قياس مدي عدالة

التوزيع للموارد في مجالات الحياه المختلفة، وان قيمة معامل جيني تتراوح ما بين الصغر والواحد الصحيح، وكلما كانت قيمته صغيره دلل علي عدالة توزيع الموارد، والعكس.

حيث يوضح الجدول رقم (0) أن الموارد المائية النيلية تتركز في كل من اثيوبيا،

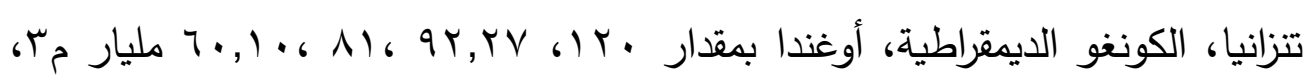

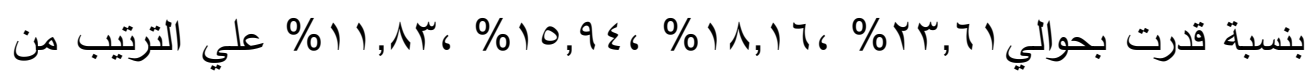
إجمالي مياه النيل المتاحة

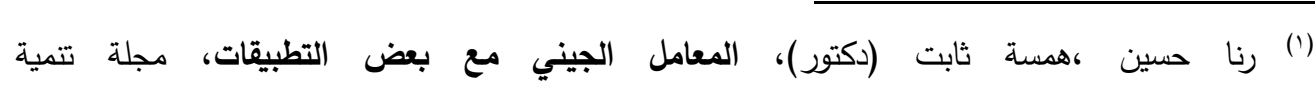

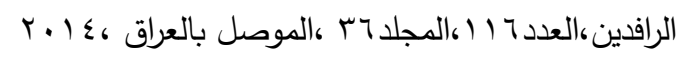


جدول رقم (•) نسبة التركز في توزيع الموارد المائية النيلية لدول حوض النيل عام V ـ Y.

\begin{tabular}{|c|c|c|c|c|c|c|}
\hline $\begin{array}{l}\text { اللموارد المائية (التجميعية } \\
\\
\text { النيلية } \\
\text { (yi) }\end{array}$ & (\%)(التجميعية لعدد & (\%) & 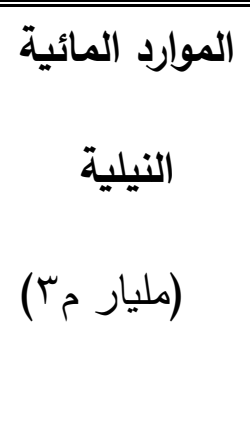 & (\%) & ( عليون نسمهد) & بيان \\
\hline$r, \Sigma V$ & r,IT & $Y, \leqslant V$ & Ir,or & $r, I r$ & $1 \cdot, \wedge 7$ & بورندي \\
\hline $0, .9$ & $\varepsilon, 0$. & $r, T r$ & •r, & r & $M, r$. & روندا \\
\hline rT, YO & 10,77 & 11,17 & $q r, r v$ & 11,17 & oV,rl & تنزانيا \\
\hline$r q, 19$ & Yo, r & $0,9 \leq$ & $r ., r$. & 9,71 & $\varepsilon q, \vee$. & كينيا \\
\hline
\end{tabular}


مجلة البحوث و الدراسات الإفريقية ودول حوض النيل - جامعة أسون - المجلد (r) - العدد ( ( ) - يناير ( r م r م)

\begin{tabular}{|c|c|c|c|c|c|c|}
\hline$\varepsilon 0,1 \mu$ & $\varepsilon 1, r$. & $10,9 \leqslant$ & N) & 10,17 & 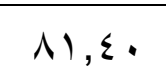 & الكونغو الديمقراطية \\
\hline 07,97 & $\leqslant 9,00$ & rی, 1 & $7 ., 1$. & A, & $\varepsilon r, \wedge \wedge$ & اوغندا \\
\hline$\Lambda \cdot, O V$ & $v \cdot, \cdots$ & (T) & ir. & $r \cdot, \leqslant 0$ & $1 \cdot \varepsilon, 97$ & اثيوبيا \\
\hline$\Delta r, \ldots$ & $V \cdot, 77$ & $1, \varepsilon r$ & $V, Y T$ & $\cdot, 77$ & $r, \varepsilon l$ & اريتريا \\
\hline$\wedge 0, \varepsilon \varepsilon$ & $V T, \cdot 1$ & $r, \varepsilon \varepsilon$ & IV,O. & r, ro & Ir,OV & جنوب السودان \\
\hline$\wedge 9, \cdot \wedge$ & $\wedge 1, \ldots$ & $r, T \varepsilon$ & 11,0 & $v, 99$ & $\varepsilon \cdot, 99$ & السودان \\
\hline $1 \ldots$ & $1 \ldots$ & $1 \cdot, 9 r$ & 00,0 & $19, \ldots$ & $9 V, 00$ & مصر \\
\hline \multicolumn{2}{|c|}{ معامل جيني * =.r, . } & $1 \ldots$ & $01 \cdot, 17$ & $1 \ldots$ & $01 T, \lambda r$ & الاجمالي \\
\hline
\end{tabular}


${ }_{i+} X_{i} \mathrm{Y} \sum-{ }_{i+}{ }_{i} \mathrm{X} X \sum$

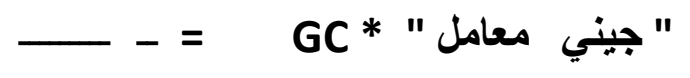

$1 \ldots$

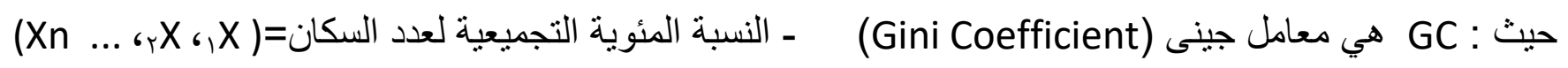

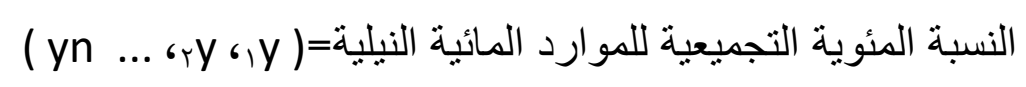

htt/www.fao.org.(FAO Stat) المصدر : جمعت وحسبت من : منظمة الأغذية والزراعة(FAO)، قاعدة بيانات

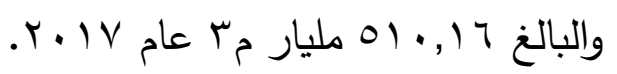


في حين تبين من نفس الجدول أن إجمالي عدد السكان في دول حوض النيل بلغ

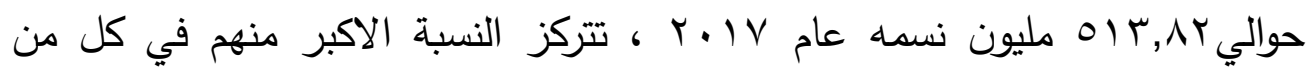

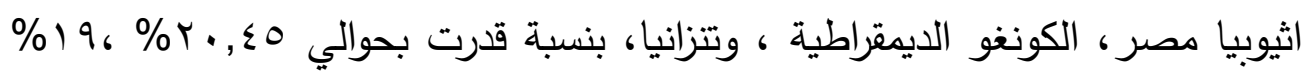

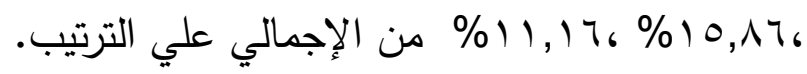

وبقياس درجة معامل (جيني) فقد بلغت نحو(9), ·) مما يثير إلى أن توزيع المياه بكمياته الحالية تميل الي العدالة التوزيعية ، ولكن لم تحقق العدالة طبقاً لقيمة معامل جيني والتي تزداد عدالة التوزيع مع انخفاض قيمته. كما يوضح منحني لوزنز والذي يعبر عن التباين في توزيع الموارد بيانياً، والذي يعبر عن مدى تطابق التوزيع الفعلي عن التوزيع الامثل ، حيث يوضح الثكل رقم ابتعاد توزيع المياه عن العدالة الي حد ما ـ (1)

شكل رقم (1) : منحنى لورنز لتوزيع الموارد المائية في دول حوض النيل في عام 
عوجان مبارك عوجان دعيم العرادة وآخرون، الوضع الراهن للموارد المائية واستخداماتها في دول حوض النيل.

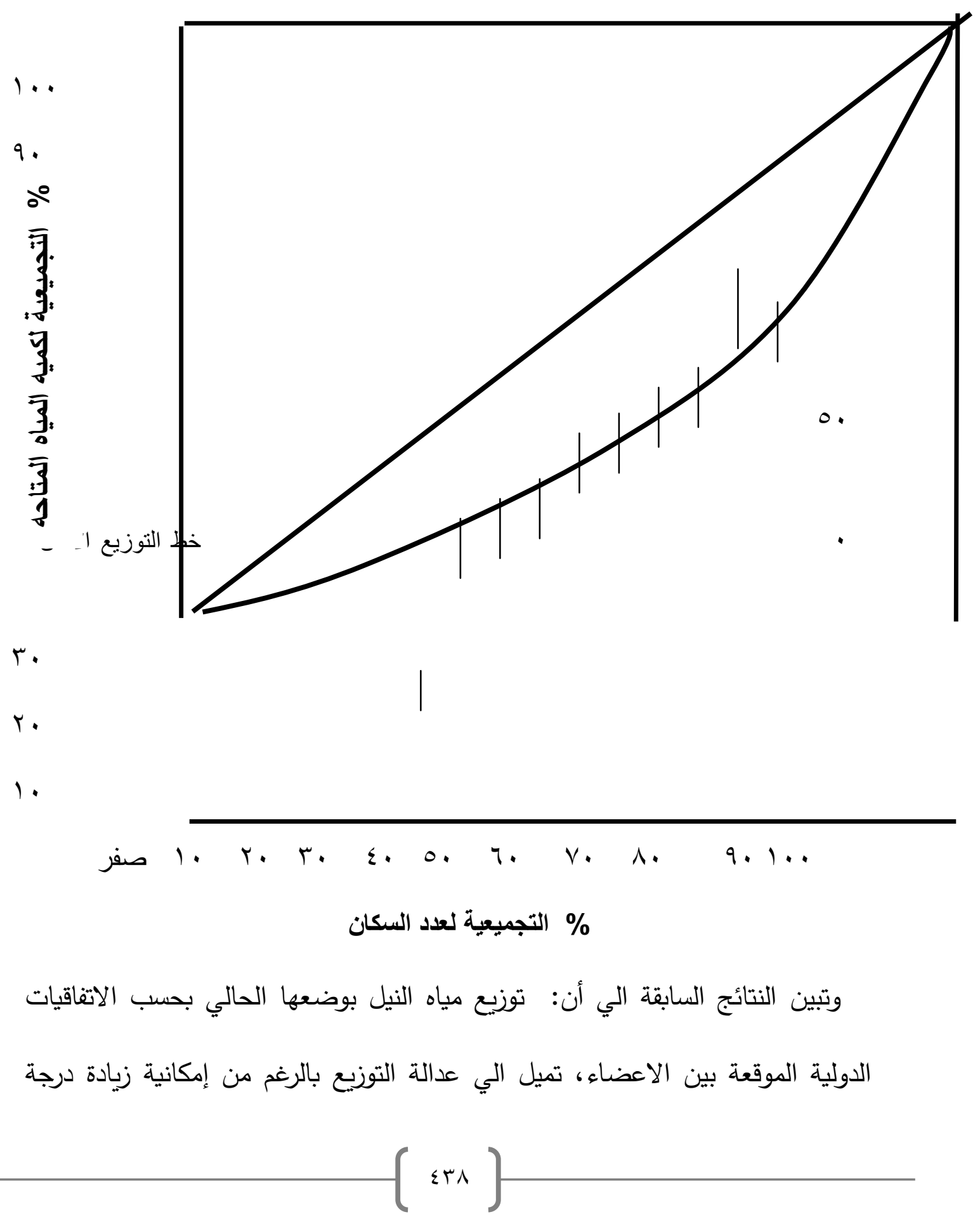


العدالة في التوزيع ، وان التوزيع الفعلي يقارب التوزيع المتالي ، ومما يدلل ابضا عدم أحقية أي دوله من انتقاص الحصص الحالية من مياه أي دوله ، وإن كانت الدول الكثيفة للسكان مثل مصر أحق من غيرها في زيادة حصتها المائية.

\section{تالثاً : الموارد المائية غير التقليدية في دول حوض النيل(').}

تعتبر الموارد غير التقليدية هي المخرج الحالي لبعض الدول لتغطيه الاستخدام في جميع القطاعات داخل الدولة ، وخصوصا عندما تكون هناك فجوة ما بين المتاح من الموارد واستخداماتها .

وتعتبر الموارد المائية في ظل المتغيرات الحالية من اكثر اهتمامات الدول ، وخاصة للدول التي تقع تحت خط الفقر المائي، فتسعى هذه الدول الى تتمية مواردها المائية الي البحث عن مصادر غير تقليديه والمتمثلة في اعادة تدوير مياه الصرف الزراعي والصرف الصناعي والصرف الصحي ، وتحلية مياه البحار

وتعتبر دول حوض النيل فيما عدا مصر من الدول التي لا تهتم في هذا المجال

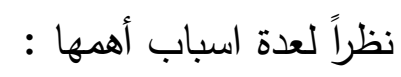

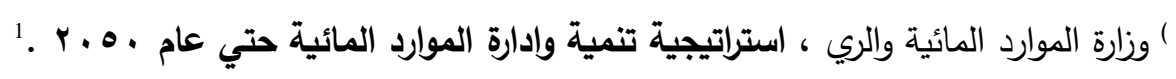


ا-وفرة المياه ووقوع اغلب الدول فوق خط الفقر المائي، فيما عدا مصر والسودان وكيبا كما تبينه البيانات في المبحث الثاني من هذا المطلب ، r- تدني البنيه التحتية الزراعية الصناعية والإنثائية، وذلك فيما يخص تدوير مياه الصرف الزراعي والصناعي والصحي. r-هناك بعض دول الحوض تعتبر دول حبيسه ،اي لا تطل علي منافذ بحريه متل اثيوبيا وروندا وبورندي واوغندا والكونغو الديمقراطية. فيما عدا ذلك تعتبر أكثر البلدان اهتماماً بتتمية الموارد المائية كل من مصر في كافة انواع تلك المصادر خلال العشر سنوات السابقة، وبالإضافة الي السودان في مجال قطاع الصرف الزراعي. ثالثاً:استخدامات الموارد المائية في دول حوض النيل. تثير بيانات جدول رقم(T)،الي توزيع استخدام الموارد المائية في دول حوض

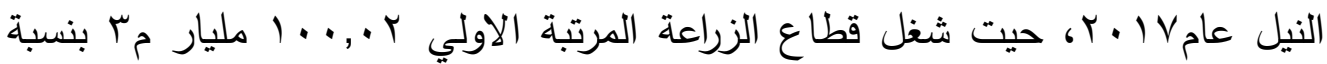

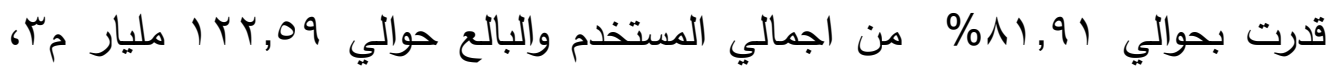

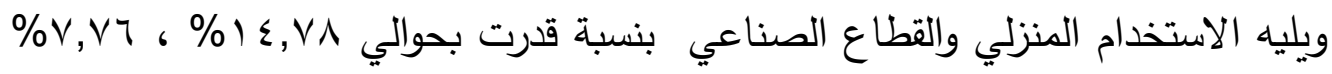
من إجمالي الموارد المائية المستخدمة علي الترتيب . 
جدول رقم (†) الاستخدام المائي وفقاً للقطاعات المختلفة في دول حوض النيل عام V V ـr.

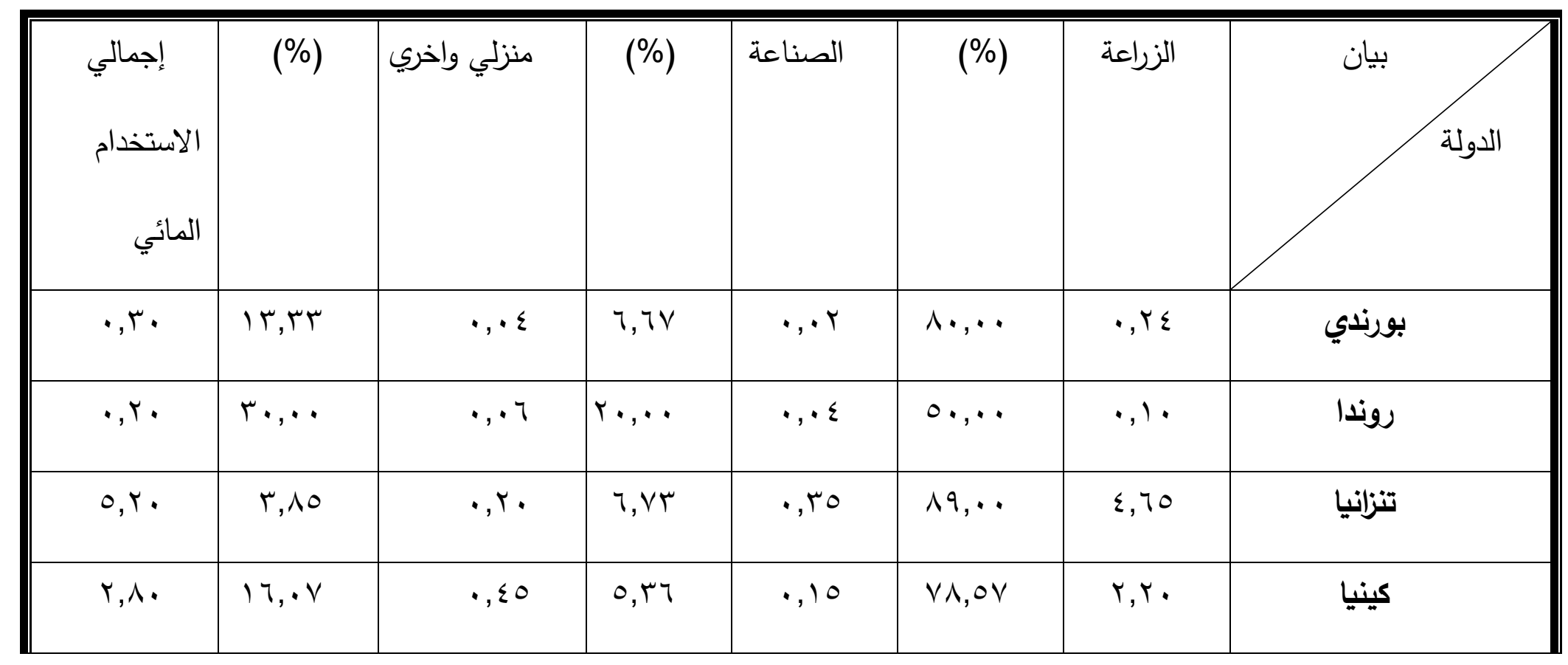




\begin{tabular}{|c|c|c|c|c|c|c|c|}
\hline $1,7 \wedge$ & & • & 1, & $\cdot, 10$ & $09,0 Y$ & $1, \ldots$ & الكونغو الايمقراطية \\
\hline$\cdot, V \cdot$ & $\varepsilon Y, \wedge\urcorner$ & $\bullet$ & $1 \varepsilon, r q$ & $\cdot, 1$ & $\varepsilon r, \wedge\urcorner$ & $\cdot, r$. & اوغندا \\
\hline 7,1 . & $11, \leqslant \wedge$ & $\cdot, V$. & $1,7 \leq$ & $\cdot, 1$ & $\wedge 7, \wedge 9$ & $0, r$. & اثيوبيا \\
\hline$\cdot, \wedge$ & ro,... & $\cdot, r$. & $q, r_{0}$ & $\cdot, .0$ & $\neg \wedge, \vee 0$ & $\cdot, 00$ & اريتريا \\
\hline 7,97 & $11,0 \leqslant$ & $\cdot, \wedge$ & $r, \wedge q$ & $\cdot, r \cdot$ & $10,0 \mathrm{~V}$ & 0,91 & جنوب السودان \\
\hline$r \cdot, 1$. & $r, q \wedge$ & $\cdot, \wedge$ & $0,9 \mathrm{~V}$ & $1, r$ & $9 \cdot, 0$ & $1 \wedge, 1$. & السودان \\
\hline$\vee \vee, \vee O$ & IT,VT & $1 \cdot, v \cdot$ & 7,90 & $0, \varepsilon$ & $\vee q, Y q$ & 71,70 & مصر \\
\hline Irr,oq & $14, \cdot 7$ & $1 \varepsilon, \vee \wedge$ & سז, & $V, V T$ & 11,71 & $1 \cdot, \cdot r$ & لي \\
\hline
\end{tabular}

الكمية: مليار مr

htt/www.fao.org.(FAO Stat) المصدر : جمعت وحسبت من : منظمة الأغذية والزراعة(FAO)، قاعدة بيانات 
وشغل قطاع الزراعة النسبة الاكبر في الاستخدام المائي في كل السودان وتتزانيا

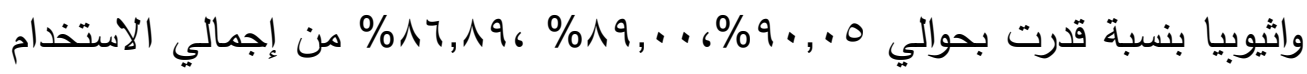
السنوي للموارد المائية بين دول حوض النيل. في حين شغل قطاع الصناعة النسبة الاكبر في الاستخدام المائي في كل من

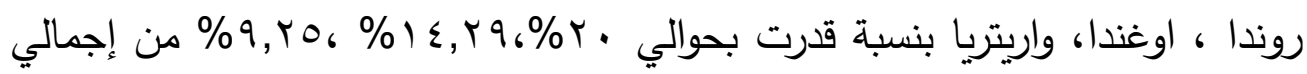

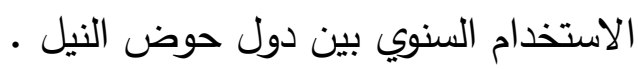

وشغل الاستخدام المنزلي والاخرى النسبة الاكبر في الاستخدام المائي في كل من

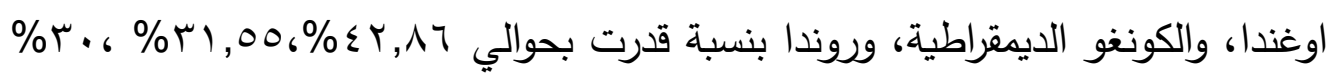
من إجمالي الاستخدام السنوي بين دول حوض النيل. وهذه النتائج توضح أن قطاع الزراعة يشغل المرتبة الاولي في الاستخدام المائي في كل دول حوض النيل، في حين ان القطاع الصناعي يشغل المرتبة الثالثة والأخيرة ، وهذا يبين عدم التقدم الصناعي لهذه الدول، وغيرها من اسباب الاستخدام التقليدي في ري الزراعات ، وارتفاع نسبة الاستخدام المنزلي والأخرى في بعض الدول، الأمر الذى 
يدعوا الي العمل على رفع كفاءة الاستخدام كافة القطاعات ، وقطاع الزراعة والاستخدام

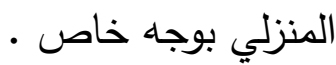

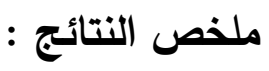

تشير نتائج البحث ان مساحة الحوض المائي في هذه الدول والذي يعني مساحة

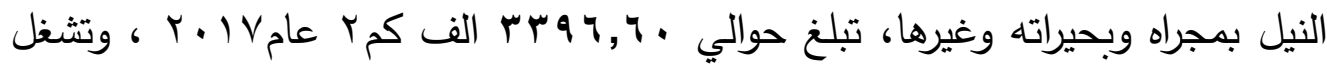
السودان وجنوب السودان واثيوبيا الحيز الاكبر من مساحة الحوض المائي بحوالي

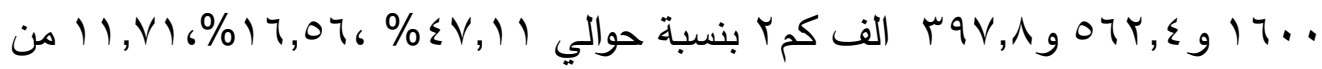
إجمالي مساحة الحوض المائي علي الترتيب ، فيما تعتبر روندا الاقل مساحة للحوض المائي بنسبة تبلغ حوالي • ع, • \% من إجمالي المساحة الكلية للحوض المائي. وتبرز النتائج أن الكونغو الديمقراطية تحظي بالنصيب الاكبر علي الاطلاق من المياه السطحية في دول حوض النيل ، ولكن لا يعتبر نهر النيل الابيض الذي تشترك في حوضه المائي المصدر الاساسي لهذه الموارد ، بل يعتبر نهر الكونغو هو المصدر الاساسي، ذلك بعكس اثيوبيا الذي يعتبر النيل الازرق وروافده، والذي ينبع منها هو المصدر الاساسي للمياه السطحية في اثيوبيا حيث تبلغ مواردها من نهر النيل

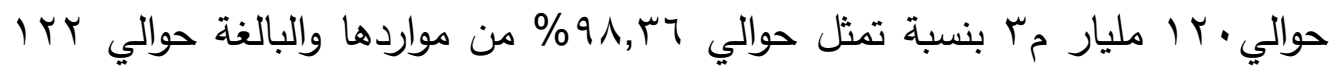


وعند دراسة توزيع المياه الجوفية المتجددة والغير متجدده في دول حوض النيل

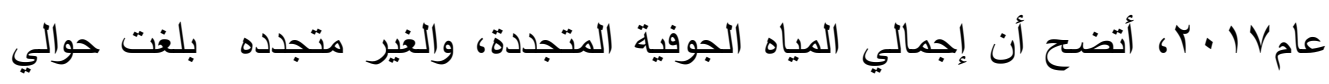

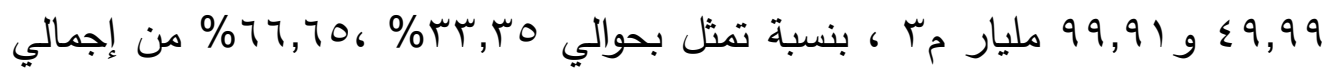
المياه الجوفية في دول حوض النيل. وبتقدير درجة معامل (جيني) لاستبيان العدالة التوزيعية للموارد المائية النيلية، فقد بلغت نحو(9 ז, ·) مما يثير إلى أن توزيع المياه بكمياته الحالية تميل الي العدالة التوزيعية ، ولكن لم تحقق العدالة طبقاً لقيمة معامل جيني والتي تزداد عدالة التوزيع مع انخفاض قيمته.

وأوضحت النتائج : أن الموارد المائية في ظل المتغيرات الحالية من اكثر اهتمامات الدول ، وخاصة للدول التي تقع تحت خط الفقر المائي، فتسعى هذه الدول الى تتمية مواردها المائية الي البحث عن مصادر غير تقليديه والمتمثة في أعادة تدوير مياه الصرف الزراعي والصرف الصناعي والصرف الصحي ، وتحلية مياه البحار ، وتعتبر دول حوض النيل فيما عدا مصر من الدول التي لا تهتم في هذا المجال نظراً لعدة اسباب تم سردها في متن البحث. وبدراسة توزيع استخدام الموارد المائية في دول حوض النيل عام Y •r، حيت

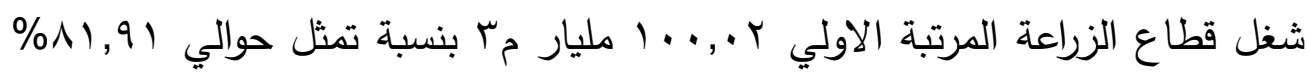

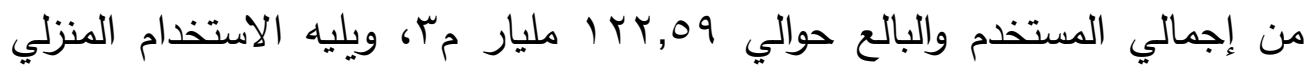




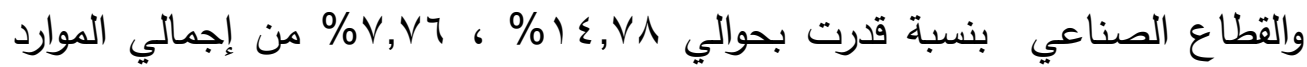
المائية المستخدمة علي الترتيب .

\section{ومن خلال تلك النتائج يوصى البحث بالتالي:}

1- سعى دول حوض النيل الي التعاون المشترك في تتمية واستخدام الموارد المائية للوصول الي الكفاءة المثلى في استغلال كافة الموارد المائية بمصادرها المختلفة ومنع الفاقد منها بأنواعه المختلفة.

r- ترشيد الاستخدام المائي في قطاع الزراعة ، وذلك باستخدام طرق الري الحديثة ، ومحاولة زراعة اصناف غير مستهلكة للماء، وخاصة في الدول التي قاربت او تحت خط الفقر المائي.

r- زيادة الاهتمام بالموارد المائية غير التقليدية وخاصة الصرف الزراعي والصحي ، وذلك باعتبار ان اغلب دول حوض النيل دول حبيسة لا تتطل علي بحار لتحلية مائها، وذلك عند وصول أي من دول حوض النيل الي خط الفقر المائي. 


\section{المراجع والنشرات}

ا-رنا حسين ،همسة ثابت (دكتور)، المعامل الجيني مع بعض التطبيقات،مجلة تتمية

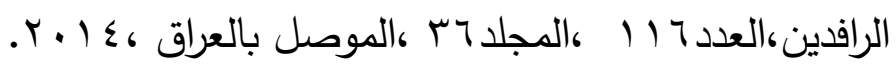

r-فوزي فوزي ابوالعنين، الوضع الراهن للأمن المائي في دول حوض النيل في ظل المتغيرات المعاصرة، المجلة المصرية للاقتصاد الزراعي، المجلد (ع ب)، العدد(ع)،

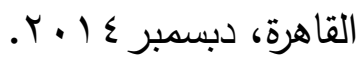

ب-منار عزت مححد، وفاء عبدالكريم محم، الموارد الاقتصادية المتاحة للتنمية الاقتصادية في دول حوض النيل ومدي امكانية التعاون المشترك بينهم ، مجلة الإسكندرية للعلوم

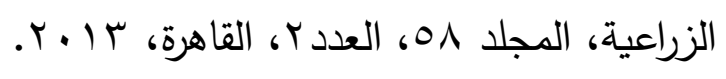

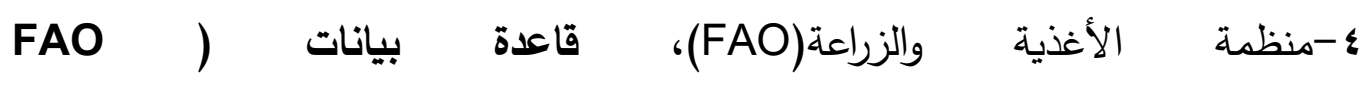

\section{.htt/www.fao.org.(Stat}

ه-هاني نبيل صبحى شراب، الامن المائي العربي ـ نهر النيل نموذجا، رسالة ماجستير، كلية الاقتصاد والعلوم الإدارية، جامعة الازهر ،غزة ، 10 . ب.

צ-وزارة الموارد المائية والري ، استراتيجية تنمية وادارة الموارد المائية حتي عام • ه ؟ ، القاهرة ،دبسمبر 7 ا ـ ץ. 